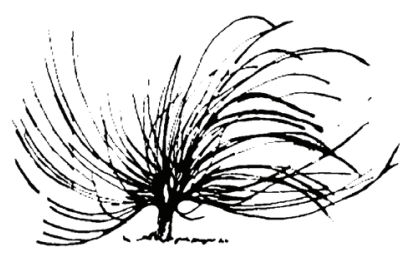

\title{
Sistema educativo costarricense: ¿Puerta o barrera para el pensamiento crítico?
}

\author{
Andrés Ariel Robles Barrantes ${ }^{1}$ \\ Universidad Nacional \\ Heredia, Costa Rica \\ arielroba@outlook.com
}

\begin{abstract}
Resumen
Para intentar comprender las pretensiones de un sistema, en otras palabras, la supuesta visión de un Estado, una de las formas más eficientes y confiables de análisis se materializa en el estudio crítico del sistema educativo establecido en un país, provincia o región. Porque es el sistema educativo quien prepara el futuro de una sociedad. Sin lugar a dudas, los estudios pueden partir de diferentes previstas. Esto quiere decir que un mismo fenómeno se puede abordar con diversos enfoques que al finalizar resulten en conclusiones muy lejanas unas con otras, a pesar de partir de la misma situación o fenómeno de investigación. Es por esto importante aclarar que este ensayo analiza el sistema educativo costarricense desde un punto de vista crítico, partiendo desde una perspectiva de estudio sobre el fortalecimiento de un pensamiento crítico en la población y de esta forma comprender a qué intereses responde el sistema educativo costarricense,
\end{abstract}

\section{(c) (1) (1) $\Theta$}

Recibido: 18 de noviembre de 2016-Aprobado: 3 de octubre de 2017

http://dx.doi.org/10.15359/rep.12-2.1

1 Profesor en el programa CI-UNA de la Universidad Nacional, Sede Regional Brunca. Master en Gestión Educativa con Énfasis en Liderazgo de la Universidad Nacional. 
entendiendo cuál es su rol dentro del sistema económico neoliberal que se impulsa en Costa Rica.

Palabras clave: sistema educativo, pensamiento crítico, sociedad, análisis.

\begin{abstract}
The critical analysis of an educative system is one of the most efficient ways of understanding the expectations of a state, province or region. This is possible because the educational system prepares a society for the future. Without any doubt, studies can come from different perspectives in education, which means that the same phenomenon can be analyzed from different aspects and end up in very diverse conclusions even though they come from the same research problem. For this reason, it is important to clarify that this essay analyzes the educational system from a critical point of view, starting from a perspective of analysis based on the strengthening of the critical thinking of the population and understanding which the Costa Rican objectives are.
\end{abstract}

Keywords: educational system, critical thinking, society, analysis.

\title{
Rol del sistema educativo en la sociedad
}

Para intentar comprender las pretensiones de un sistema, en otras palabras, la supuesta visión de un Estado, una de las formas más eficientes y confiables de análisis se materializa en el estudio crítico del sistema educativo establecido en un país, provincia o región, porque es el sistema educativo quien prepara el futuro de la sociedad y, por tanto, requiere suma atención.

Sin lugar a dudas, los estudios pueden partir de diferentes previstas. Esto quiere decir que un mismo fenómeno se puede abordar con diversos enfoques que al finalizar resulten en conclusiones o visiones muy lejanas unas con otras, a pesar de partir de la misma situación o fenómeno de investigación. Es por esto importante aclarar que este ensayo analiza el sistema educativo costarricense desde una perspectiva de estudio sobre el fortalecimiento de un pensamiento crítico en 
la población y de esta forma comprender a que intereses responde el sistema educativo eostarricense, entendiendo cuál es su rol dentro del sistema económico neoliberal que se impulsa en Costa Rica desde el siglo pasado.

Es necesario aclarar que este planteamiento respeta los diversos criterios que puedan existir en torno al éxito o fracaso que este sistema educativo particularmente tenga en otras áreas o enfoques de estudio. Sin embargo, se centra en el análisis del fortalecimiento del pensamiento crítico, ya que es una de las formas de liberación del ser humano hacia una sociedad con menos estereotipos y limitaciones, además de brindar un mayor entendimiento del mundo y su correlación de fuerzas. Entendiendo por fuerzas, los poderes económicos, sociales y culturales hegemónicos bajo el dominio del sistema neoliberal. Es finalmente el pensamiento crítico el que brinda la oportunidad de que tanto educadores como educandos se embarquen en un diálogo pedagógico profundo para la construcción de una sociedad con mayores capacidades intelectuales, donde se pueda lograr el entendimiento de la importancia que tienen la equidad, justicia y dignidad. Sociedad donde se brinde la oportunidad de una vida digna a las clases sociales más limitadas y explotadas del país.

\section{Educación y pensamiento crítico}

La verdadera educación transforma a quienes participen en ella, para esto es necesario romper inicialmente con la dicotomía tradicional del educador como sabedor del todo, único y dueño de la razón, y el educando como una mente vista al igual que una caja vacía que necesita ser llenada. Esto quiere decir que el planteamiento de la educación transformadora parte de que ambos, estudiantes y educadores, pueden ser transformados. Implica, llegar a vivir un proceso donde la dinámica dialógica se realice desde un mismo nivel entre educadores y educandos, convirtiéndose en un requisito indispensable para la práctica de una educación transformadora. Dicho en otras palabras, en este escrito se comprende como una pedagogía transformadora la que se caracteriza por la capacidad de crecimiento en el razonamiento crítico, brindando el fortalecimiento de la capacidad de análisis intelectual que lleva a la libertad del individuo y de su entendimiento con respecto a la situación social que posee. Es el método que deja de lado la educación bancaria 
explicada por Paulo Freire (1970) en su libro Pedagogía del Oprimido como "la narración, cuyo sujeto es el educador, quien conduce a los educandos a la memorización mecánica del contenido narrado... la narración los transforma en "vasijitas", en recipientes que deben ser "llenados" por el educador" (p. 78). Dejando este método tradicional descrito por Freire para transformarse en una educación como un medio libertador y analítico de la realidad del individuo frente a la sociedad, sus limitantes y condiciones tanto subjetivas como objetivas y finalmente su desempeño como opresor u oprimido de acuerdo con su rol social. Entendiendo incluso el sistema y el currículo educativo como una construcción que se encuentra llena de limitantes, como lo describe Penalva (2006), en el artículo La Construcción Social del Currículum: Análisis Crítico de los Aspectos Semánticos y Epistemológicos, "se ignora la función ética y política del currículum. No aporta base racional para criticar, como mínimo, los hechos" (p. 345). Es en este contexto de análisis dialéctico que surgen preguntas como: ¿qué tan transformador es el sistema educativo?, ¿qué tanto influye en el fortalecimiento del pensamiento crítico? y ¿a qué intereses verdaderamente responde?

Para desarrollar un análisis más profundo es necesario partir de una descripción básica y general que facilite la comprensión del surgir de los sistemas educativos para luego definir a grandes rasgos como se encuentra establecido el sistema educativo costarricense, el cuál desde sus orígenes ha vivido una serie de cambios y modificaciones que se enmarcan en un ámbito público, cuyos cimientos se podría decir que están constituidos en un sistema inclusivo al servicio de las grandes mayorías, un sistema caracterizado por brindarles cobertura tanto a los hijos de los campesinos como a los hijos del presidente, sin distinción ni discriminación alguna. Pero a pesar de esto, con el paso del tiempo ha sido influenciado por las corrientes políticas y los intereses mercantiles de la época. Cambios que se concretan a través de sistemas curriculares que responden a los intereses de quienes gozan del poder. Tal como lo plantea Gimeno (2010) en el libro La Función Abierta de la Obra y su Contenido, "las prácticas dominantes en un momento dado también lo condicionan a él; es decir, que el currículum es a la vez instituido en su realización" (p. 12). Dejando clara la capacidad que tienen quienes dominan para manejar el sistema de acuerdo con sus intereses. 


\section{Sistema educativo: planteamientos iniciales}

Los orígenes de las primeras iniciativas de educación sistematizada en Costa Rica y en el resto de Latinoamérica tienen una profunda relación con los modelos educativos que se utilizaban en Europa, esto debido a que fue una de las tantas herencias de la época de conquista. Los primeros pasos de estos sistemas educativos europeos se remontan a la segunda mitad del siglo XIX donde se dan iniciativas en la constitución de un medio de cobertura escolar a partir de las influencias de la Ilustración y la Revolución Francesa (Delgado, 1994). Por ejemplo, el contexto en el que surge el modelo educativo español es bajo el consenso entre diversas fuerzas políticas liberales y conservadoras en la nación. En esta época se desenvolvía un sistema que nacía respondiendo a las condiciones políticas, sociales y económicas, esto ante el paso que se daba de una sociedad feudal a una precapitalista. Esta evolución a un rol educativo sistematizado planteó desde sus orígenes la generalización de estudios para que los individuos respondiesen a las pretensiones de las clases gobernantes, de acuerdo con sus fines e intereses. Impulsando a través de ese instrumento político instruir el pensamiento con respecto a lo que necesitaban de las masas a su cargo.

Retomando nuevamente el caso de España debido a su influencia en la conquista latinoamericana, su sistema educativo nace en la Constitución de 1812 después de que la educación se encontraba en manos de la Iglesia católica. En esta constitución se toma la idea de educación como un sistema en el cual la organización, la financiación y el control debe intervenir el Estado, con esto se sientan las bases del Sistema Educativo Español. Para la creación de un sistema educativo con planteamientos significativos en términos de cobertura se necesitó gran influencia de la Constitución de 1812, como lo establece el Ministerio de Educación, Cultura y Deporte de España (2004) en el libro Evolución del Sistema Educativo Español "cabe señalar su defensa de la universalidad de la Educación Primaria para toda la población sin excepciones y la uniformidad de los planes de enseñanzas para todo el Estado" (p. 1). A pesar de estos planteamientos, después de una serie de conflictos sociales no se logra avanzar en la conformación del sistema educativo, las mejoras llegan hasta que se obtiene la Ley de Instrucción Pública de 1857, conocida como la Ley de Moyano debido al nombre del ministro que impulsó su aprobación. Esta fue producto del consenso 
entre las fuerzas políticas y simboliza la consolidación del sistema educativo liberal y la estabilización de la instrucción pública (Ministerio de Educación, Cultura y Deporte de España, 2004). Es fundamental comprender los orígenes de este modelo debido a que posteriormente muchos de sus planteamientos son llevados a América a partir de su supuesto descubrimiento.

\section{Descripción general de los orígenes del sistema educativo de Costa Rica}

Las raíces del sistema educativo costarricense parten del mismo vínculo que en el resto de América, las primeras escuelas surgieron como resultado de la época colonial y sus objetivos eran enfáticamente la enseñanza del cristianismo. No fue hasta entre los años 1813 y 1814 que surgieron las primeras escuelas ubicadas en el centro del país y enfocadas a brindar la educación formal solo a hombres. Datos expresan que se inició con un planteamiento de mayor seriedad y después de varios esfuerzos con alrededor de 35 escuelas primarias, catalogándose como el primer avance en la construcción de un posible sistema educativo costarricense (Molina, 2007). Previamente existieron iniciativas que se pueden constatar entre los años 1714 y 1788 donde se encuentran registros del pago a docentes, en estos casos solo los hijos de la clase pudiente de aquellos años podían recibir esta formación, en su mayoría centrada en la alfabetización (OEI, 1997).

En 1814 se funda, además, la casa de enseñanza Santo Tomás que se convirtió años después en el primer centro de educación superior sólido del país. En 1844 las mujeres logran iniciar sus estudios primarios y también se inicia una visión más tecnificada de la educación. Por último, en 1890 se promulgan leyes y reglamentos enfocados a la filosofía educativa y organizativamente se toma la educación formal como un planteamiento importante en el ámbito gubernamental. En el siglo XX, en específico ya en el año 1908 se fundamenta el primer movimiento en materia pedagógica de la época, caracterizado por teorías educativas con un enfoque más humanista y centrado en el aprendizaje de los niños. Asimismo, se funda la Escuela Normal en Heredia, con el propósito de brindar una formación a los docentes por medio de un programa de capacitación de dos años. Es a partir de esta época que se efectúan diferentes reformas educativas, resultando el año 1935 en cambios con 
matices más marcados en cuanto a la formación educativa. Es en este mismo año que se realiza la llamada Misión Chilena, nombre dado a un grupo de intelectuales chilenos que dan una serie de recomendaciones al país y buscan la estructuración de distintas entidades educativas. En 1941, nace la Universidad de Costa Rica (OEI, 1997).

A partir de 1950, se inicia una serie de avances estructurales en cuanto a la prioridad del sistema educativo para el desenvolvimiento del país. Desde 1953 se dan iniciativas como la creación del Consejo Superior de Educación, la Ley Fundamental de la Educación, la reorganización de la Misión Técnica de la Unesco, la creación de un Plan de Estudios y el desarrollo del Plan de Desarrollo Educativo. Uno de los avances más simbólicos se da en 1978 con el planteamiento de la Regionalización del Sistema Educativo cuyos objetivos según la OEI (1997) fueron:

- Lograr una efectiva desconcentración del sistema administrativo vigente.

- Desarrollar convenientemente la planificación y la microplanificación a nivel regional.

- Alcanzar una verdadera racionalización de los recursos.

- Coordinar en todos los niveles, efectivamente, acciones comunes con los diferentes sectores de la Administración Pública.

- Plantear y ejecutar cambios en el contenido conceptual y en el rol de la educación, para que se ajusten a los requerimientos del proceso de crecimiento socioeconómico de la región y del país.

- Detectar la disponibilidad cualitativa de los recursos humanos regionales.

- Consolidar las identidades nacional, regional y local.

- Ofrecer oportunidades educativas para lograr la formación de ciudadanos responsables y conscientes de sus deberes y derechos, según las necesidades regionales y las oportunidades de trabajo.

- Estimular y ejecutar toda innovación educativa que mejore la calidad de nuestra educación.

- Contribuir al desarrollo de una capacidad científico-tecnológica regional (p. 5).

Los años 80 del siglo pasado se ven plagados de diferentes reformas y planteamientos. Uno de los más llamativos que perdura hasta la 
actualidad es la reimplantación del examen de Bachillerato, prueba aplicada a los estudiantes para la obtención del grado en educación media. Según la OEI (1997) esta reactivación consistió en "pruebas no como un fin en sí mismo, sino como un medio para reactivar la vida educativa del país, de involucrar en el compromiso, a los alumnos, padres de familia, autoridades y a toda la sociedad en general" (p. 6). Estos cambios se consolidaron en los años 90 con nuevos planteamientos curriculares.

\section{Análisis de las contradicciones del sistema educativo costarricense: años 90 del siglo pasado}

A partir de 1990 el Ministerio Público plantea un enfoque educativo procesal, supuestamente concentrado en el educando y su camino en un ideal constructivista del aprendizaje. En otras palabras, se cambia de un sistema inductivo o conductista a un proceso constructivo; la OEI (1997) lo describe como "una visión constructivista del aprendizaje que coloca la atención, más que en el qué, en el cómo aprender" (p. 6). Sin embargo, se mantienen las imposiciones conductistas al educador y la relación educador-educando del sistema tradicional, algo que es expresado luego en la misma fuente, "debe entenderse que se propone un proceso de cambio, desde lo inductivo a lo constructivo, en tanto el docente sigue pensando inductivamente" (p. 6). Si se analiza el trasfondo de este planteamiento es posible deducir que a pesar de que se cambia la metodología de abordaje pedagógico, se sigue manteniendo un mismo sistema, enfocado en la corriente de pensamiento que posiciona al educador como único sabedor y dirigente del proceso cognitivo. Incluso, aunque esta reforma se traza con objetivos para el mejoramiento y desarrollo de la calidad de vida, tanto individual como social, no se crean los espacios idóneos para facilitar un proceso pedagógico que invite a la construcción de un pensamiento que pueda impactar el comportamiento social y, por ende, la calidad de vida bajo la investigación científica y la construcción del pensamiento. Algo que solo puede ser logrado con el fortalecimiento de la decodificación de la panorámica social y de la realidad que vivencian los individuos para que por medio de su propio descubrimiento y liberación avancen en la construcción de una sociedad que comprenda los fenómenos que la envuelven y su desarrollo, entendiendo su papel y engranaje dentro del sistema social. 
Además, estas políticas continúan el planteamiento unidireccional donde los objetivos, planes y programas de estudio siguen siendo impuestos desde la institucionalidad y no desde un consenso donde participen con mayor propiedad los actores primordiales del proceso pedagógico que son los educadores y estudiantes. Se puede identificar la necesidad de la contextualización incluso en el impulso gubernamental que pretende desde sus orígenes tratara la población de forma estandarizada, a pesar de las múltiples situaciones contextuales que pueden hacer diferentes a los actores, sus necesidades y papeles a lo largo del territorio. Un ejemplo claro es la implantación de un examen de Bachillerato estandarizado que en ningún punto se contextualiza, aplicándose este tanto en zonas urbanas a colegios de la gran capital y en condiciones favorables como a colegios en zonas rurales y territorios indígenas llenos de limitaciones. Estas pruebas son enfatizadas en la capacidad de la evaluación del conocimiento meramente técnico, como una respuesta al sistema de mercado, donde la comprobación de cierto conocimiento o habilidad es utilizada como un producto vendible del país ante las corporaciones o estándares internacionales.

Es importante señalar que desde los objetivos que se plantearon para la regionalización de la educación en 1978 es posible inferir que los fines de la pedagogía costarricense han sido el desarrollo socioeconómico a partir de un enfoque en la formación técnica. Es decir, el desarrollo del individuo como un ser intelectual y crítico no ha sido una meta para la clase gobernante del país, esto porque a vivas luces el planteamiento es que a partir de la formación técnico-científica se pueda brindar herramientas necesarias a la población para tener una mejor calidad de vida.

Para entender este fenómeno es necesario comprender cuál ha sido el concepto de calidad de vida manejado desde la clase gubernamental, este en apariencia es visto desde el análisis social como la capacidad de que los individuos cuenten con bienestar económico, salud y acceso a servicios básicos. Una de las primeras definiciones oficiales se puede encontrar en la emitida por el Ministerio de Educación Pública (MEP) desde la OEI (1997) donde se define calidad de vida como, "el bienestar general en todas las dimensiones que define al individuo: física, social, económica, profesional y espiritual" (p. 8). Con base en este concepto se puede decir que quien posea en Costa Rica estos requerimientos goza de una calidad de vida. El sistema educativo responde 
entonces a este criterio, dejando de lado el desarrollo intelectual porque no representa ninguna incidencia dentro de la supuesta calidad de vida establecida oficialmente, como resultado, en pocas palabras, el sistema educativo se centra solo en la formación técnica viendo al individuo más que como un ser pensante como un robot que debe estar listo para funcionar y mientras funcione, no importa que no piense. Este fenómeno se puede achacar a la necesidad del sistema educativo por responder a los servicios que exige el mercado internacional como lo establece la OEI (1997), "Como contribución al desarrollo sostenible de la nación, se plantea coadyuvar en la formación de los recursos humanos a efectos de elevar la competitividad y la eficiencia del país, posibilitando así su inserción exitosa en el mercado internacional" (p. 8). Ante esta presión de carácter geopolítico, el MEP responde a los intereses gubernamentales con un planteamiento que continua hasta la actualidad.

Es entonces de suma importancia en estas discusiones comprender que el sistema educativo tiene una relación totalmente compenetrada con la política económica de un país. El funcionamiento en este sentido debe ser leído de acuerdo con los intereses que la clase gobernante tiene para la nación. Es decir, la política económica rige y marca las reglas del mercado en el que el país se inmiscuye y que a la vez este mercado está influenciado y estrechamente ligado a la geopolítica. El papel del sistema educativo dentro de esta dinámica es suministrarle al mercado las personas competentes para el desarrollo del país. Sin duda alguna una de las preocupaciones en esta lectura de la realidad es el posicionamiento del mercado por encima de la calidad de vida del ser humano y no a la inversa. O sea, el mercado domina al ser humano y no el ser humano al mercado.

\section{¿Qué exige el mercado del sistema educativo?}

Sin lugar a dudas la educación en la mayoría de países de América se ha visto permeada por una dinámica comercial donde los sistemas educativos responden a los intereses mercantiles. Un claro ejemplo de estas persecuciones se ve en el fortalecimiento de la educación técnica que representa la posibilidad de contar con personas con capacidades para brindar servicios de calidad pero cuya categorización académica equivale a un salario bajo, de esta manera las grandes corporaciones plantean la formación técnica como una nueva dinámica de mano de obra barata. 
Otro ejemplo son los modelos de educación dual de corte centroamericano donde los estudiantes brindan sus servicios poniendo en práctica, en muchos casos de manera gratuita, el conocimiento adquirido dentro del sistema educativo. Con este modelo las empresas aprovechan las pasantías de los estudiantes a costos mínimos, dejando de lado las regulaciones y las posibles intervenciones estatales que busquen garantizar una educación de calidad. Incluso en muchos casos se pretende eliminar la figura del docente y sustituirla por un encargado de la empresa. COLYPRO (2015) en un informe sobre la educación dual establece que

todo proceso formativo requiere del manejo de habilidades, destrezas, competencias y un marco ético que lo oriente, que permita construir procesos de enseñanza y aprendizaje que son propios de la labor docente. Si la persona a cargo no posee la debida formación podría incurrir en un inadecuado acompañamiento en detrimento del derecho de una educación de calidad para la persona estudiante (p. 29).

En este informe se visibilizan las implicaciones que podrían tener los estudiantes.

Está claro que el mercado pide menos personas pensantes y más robots que realicen las labores definidas por las grandes corporaciones con la mayor efectividad y a la menor inversión económica. Ante esto los países con mayores limitaciones económicas compiten unos con otros por brindar los estándares necesarios. En esta dinámica, la formación para el fortalecimiento del pensamiento crítico pasa a un segundo plano, donde no solo se deja de poner en práctica, sino también es vista como algo negativo, ya que el razonamiento se vuelve una herramienta para que la población defienda sus derechos e intereses y comprenda con mayor claridad el funcionamiento de la sociedad y sus fenómenos.

\section{Conclusiones generales}

Es necesario comprender que el modelo educativo costarricense ha sido considerado como un sistema vanguardista con respecto al resto de Centroamérica. Primero, Costa Rica es uno de los países de la zona con un mayor presupuesto destinado a la educación. Es el país con el 
menor grado de analfabetismo y cuenta con los grupos con menor número de estudiantes por docente (CCEC, 2007). Esto da claras muestras de cómo el modelo costarricense da un panorama de lo que se puede ver y replicar en el resto de la región.

Muchos de los sistemas educativos centroamericanos han tenido que enfrentar grandes crisis políticas, económicas y sociales. Un pasado de tremenda convulsión armada entre diferentes actores sociales influyó en que también los sistemas educativos se vieran afectados. Se suman además las grandes dificultades que tienen los Estados que se encuentran limitados en términos económicos para poder brindar servicios de cobertura nacional y libre acceso.

Los docentes también enfrentan problemas de bajos salarios y un desprestigio a su labor profesional. Además, su labor docente ha sido limitada, por los enfoques de educación bancaria al servicio mercantil, a ser unos simples facilitadores de recursos o procesos, sin capacidad de incidir en la formación educativa en términos investigativos y de generación de razonamientos. Sin embargo, es necesario un educador que logre incidir de forma diferente al igual que lo plantean Nayive y León (2005) en el artículo Perspectiva Critica de Paulo Freire y su Contribución a la Teoría del Currículo, "los educadores deben comprender el papel que asume la escuela al unir el conocimiento con el poder, para aprovechar ese rol en el desarrollo de ciudadanos críticos y activos" (p. 164).

Se solapan los problemas incluso a las academias universitarias donde de nuevo el docente se convierte en una persona que maneja de forma técnica su profesión, pero que intelectualmente no tiene la preparación para asimilar muchos fenómenos sociales. Tal vez por el fenómeno que vivieron muchas universidades al pasar de ser secundarias a centros de educación superior. Vezud (2007) en su artículo La Formación y el Desarrollo Profesional Docente frente a los Nuevos Desafíos de la Escolaridad plantea que

en muchos casos la formación se elevó de nivel pero las instituciones siguieron funcionando de manera similar a las escuelas secundarias de las que emergieron, con relaciones infantilizadas entre docentes y estudiantes y vínculos con el saber que reproducen la lógica escolar, el peso de la autoridad y el rol de docente en detrimento de la autonomía de los estudiantes, del desarrollo de sus capacidades de investigación y construcción de conocimientos (p. 7). 
Los sistemas además por sus características se basan en la división basada en competencias representadas y divididas por diferentes materias o clases. Cada materia enfocada en un área de estudio que debe ser manejada por diferentes educadores. Enfoque donde el conocimiento no es visto como un todo, sino por divisiones, en el cual el educador no debe ser un intelectual sino un técnico en la materia. Una estrategia muy vieja del mercado para mantener bajo su dominio la fuerza de trabajo. En el pasado dicha fuerza era física y esta práctica era notoria en las fábricas industriales. Por ejemplo, para hacer camisetas, se tenían personas cosiendo, mientras otras personas diferentes estaban pegando botones y así con cada parte del proceso. Al final, ninguna sabía cómo se hacía el todo, solo sabían hacer su parte. Lo mismo sucede en la actualidad con este fenómeno en los trabajadores de la educación, especialmente la educación media. Ya la fuerza no es física, sino mental, sin embargo, el mecanismo de control es el mismo, el profesor de matemáticas no sabe de literatura y el de literatura no sabe de matemáticas. Al final todos son expertos técnicos de un área de estudio, pero no sujetos integrales con un razonamiento intelectual profundo de su situación social.

El pensamiento crítico como motor de una sociedad intelectual con mayores capacidades de raciocinio ha sido delegado por las fuertes corrientes neoliberales que buscan de la educación simplemente la consolidación de un sistema que prepara lo que al gran capital y a los procesos globalizadores les funciona. Es en este sentido fundamental concluir que el sistema educativo pasa a tener un comportamiento industrial donde el educando es tratado como un producto y cada año en el sistema es una parte de su ensamble para al final terminar con un recurso del cual el mercado al igual que una camiseta, puede sacar provecho y luego desechar.

En el sistema educativo costarricense los libros para el desarrollo de la clase o sistemas se han vuelto la voz última del conocimiento, el educador ha pasado a ser simplemente quien aplica las prácticas de un libro, alguien que en muchos casos no invita a pensar más allá de lo que dice el texto. Como lo plantea Gimeno (1998) en su libro El Currículum: Una Reflexión Sobre la Práctica, los educadores deberían

ser capaces de analizar y cuestionarse las condiciones que delimitan las prácticas institucionalmente establecidas, analizando sus supuestos, y promoviendo alternativas más acordes con modelos 
educativos más adecuados con las necesidades de los alumnos y con una sociedad más democrática y justa (p. 56).

Sin duda estos planteamientos están muy lejanos de la realidad que se vive en las aulas de Costa Rica donde ninguna práctica institucional pareciera ser cuestionada.

Ante esta realidad queda claro que el sistema educativo de Costa Rica no constituye ningún canal para el crecimiento crítico de la población. Es muy por el contrario una herramienta que busca el control y la formación en torno a habilidades blandas que no despiertan en el individuo ningún punto de vista crítico al respecto. Sin embargo, está dentro de la capacidad del docente generar pequeños cambios, fisuras mínimas al sistema, marcar la diferencia. Cada docente tiene la oportunidad dentro de las aulas de maniobrar en la aplicación de una pedagogía diferente a la que exige el currículum educativo. Está claro que él hacerlo involucra un esfuerzo extra de los docentes, pero debe existir la esperanza de que en algún momento la lucha por el razonamiento crítico será un fin dentro del proceso educativo del país. Un momento en que se repiense la labor del educador y los procesos pedagógicos, de esta forma tal vez pensar con mayor seguridad en un sistema que tenga como meta primordial crear nuevas formas de pensamiento que involucren el crecimiento hacia una sociedad más solidaria, justa, tolerante, una sociedad más humana y capaz de razonar mejor sus dificultades y superar sus letargos.

\section{Referencias}

Colegio de Licenciados y Profesores en Letras, Filosofía, Ciencias y Artes. (2015). Informe de Proyectos de Ley sobre la Educación Dual en Costa Rica. San José: COLYPRO.

Coordinación Educativa y Cultural de Centroamérica. (2007). Estadisticas de Educación de los Países Centroamericanos. San José: CCEC.

Delgado, B. (1994).Historia de la Educación en España y América. Madrid: Fundación Santa María.

Freire, P. (1970). Pedagogía del Oprimido. Montevideo: Tierra Nueva. Gimeno, J. (1998). El currículum: Una Reflexión sobre la Práctica. Madrid: Ediciones Morata, S. L. 
Gimeno, J. (2010). La Función Abierta de la Obra y su Contenido. Madrid: Ediciones Morata, S. L.

Ministerio de Educación, Cultura y Deporte de España (2004). Evolución delSistema Educativo Español. Madrid: MECD/CIDE.

Molina, I. (2007). Educación y sociedad en Costa Rica: de 1821 al presente (Una historia no autorizada). Diálogos Revista Electrónica de Historia, Edición especial, 1-175.

Nayive, L. y León, A. (2005, junio). Perspectiva Crítica de Paulo Freire y Su Contribución a la Teoría del Currículo. Educere, páginas 159-164. Recuperado de http://www.scielo.org.ve/scielo. php?script=sci_arttext\&pid=S1316-49102005000200003

Organización de Estados Iberoamericanos. (1997). Sistema Educativo Nacional de Costa Rica. Madrid: OEI.

Penalva, J. (2006, mayo). La Construcción Social del Currículum: Análisis Crítico de los Aspectos Semánticos y Epistemológicos. Revista Española de Pedagogía, páginas 343-364. Recuperado de https://dialnet.unirioja.es/servlet/articulo? codigo $=2083124$

Vezud, F. (2007, junio). La Formación y el Desarrollo Profesional Docente frente a los Nuevos Desafíos de la Escolaridad. Revista Profesorado, páginas 2-23. Recuperado de http://www.redalyc. org/articulo.oa? $\mathrm{id}=56711102$ 